\title{
Uveal effusion as a sign of myxoedema
}

\author{
J. RIGHARDSON AND M. WALSH
}

From the Eye Department, Royal Victoria Infirmary, Newcastle upon Tyne, and the University of Newcastle upon Tyne

Schepens and Brockhurst ( 1963 ) defined a "specific type of uveal effusion". The features of the condition are:

(i) Predilection for young to middle-aged males;

(ii) Spontaneous, often bilateral, annular cilio-choroidal detachment with few or no signs of anterior uveitis;

(iii) Development of slowly progressive and often bilateral non-rhegmatogenous retinal detachment;

(iv) Shifting subretinal fluid;

(v) (in some cases) Swelling of the optic disc.

The only frequent extraocular abnormalities they found, in spite of fairly intense medical investigation, were a raised cerebrospinal fluid protein without pleocytosis and some patients with "rheumatic disorder". They reported seventeen cases, including one female.

They drew attention to several previous papers reporting cases similar to their own. Stallard (1954) described six cases of "a peculiar type of retinal detachment, which is likely to involve the choroid also, which is annular, peripheral, and so dark in colour that it is sometimes misdiagnosed as a ring sarcoma of the choroid". His cases were all males between the ages of 30 and 60 and three of the six had bilateral disease. All had dark colouring of the hair and skin. No associated systemic or local disorder was present.

Lewallen (1957) reported the case of a 103-year-old Negro with chemosis, exophthalmos, and unilateral retinal detachment without breaks. The fellow eye became similarly affected but both returned to normal in 4 months without treatment.

Graham (1958) reported a case in which a 37 -year-old woman presented a complete retinal detachment, ocular hypotony, shallow anterior chamber, and posterior synechiae. Enucleation was carried out for suspected melanoma and ocular examination showed total retinal detachment, choroidal detachment reaching the scleral spur, moderate uveal congestion, and markedly thickened sclera. A retinal tear was said to be present on one occasion but subsequently could never be found. In discussing this case, Davenport (1958) described a female whose enucleated eye showed choroido-retinal detachment, congested uvea, and thick sclera, while the other eye displayed a low grade uveitis with annular choroidal detachment. Ridley ( 1958 ) also mentioned a uniocular patient with low-grade uveitis, hypotension, and anterior choroido-retinal detachment without visible retinal breaks. Rosen and Lyne (1968) reported two cases of uveal effusion: one was a localized choroidal detachment secondary to scleritis in a patient with rheumatoid arthritis; the other developed unilateral peripheral annular choroidal detachment with no retinal detachment. Thus neither fits the specific description given by Schepens and Brockhurst. Reports of bilateral low-grade uveitis associated with retinal detachment have appeared in the literature (Duke-Elder, 1966), but in the condition described by Schepens and 
Brockhurst inflammatory signs are either lacking or very sparse, and annular choroid detachments are invariably present and probably antedate the retinal detachment.

This paper describes a case of "uveal effusion" having all the features of the syndrom $\overrightarrow{\overline{6}}$ described by Schepens and Brockhurst, caused by myxoedema and cured by thyroxine.

\section{Case report}

A woman aged 49 years presented with a 6-month history of visual symptoms. She described central blind spots ("holes in the ground"). There were no other ocular symptoms and no previous ocular disease, but 25 years before at the age of 24 the patient had undergone an operation on the tongue for the removal of a bleeding posterior lingual tumour causing respiratory obstruction. $\overrightarrow{A b}$ this time she felt that her eyes became more prominent. Records of this operation are not availab but the surgeon, Mr. Philip Reading, has confirmed (personal communication) that a bleeding lingual thyroid was partially removed.

Since that time her general health had been fairly good except that she had required Caesareaif section for obstructed labour some years previously, and afterwards required treatment for vesic $\hat{y}^{2}$ vaginal fistula.

\section{Examination}

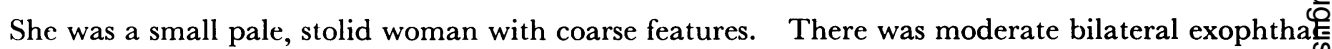
mos and right upper lid retraction (Fig. I). The exophthalmometer reading was 22.5 right and leff on a base of 105. The ocular abnormalities were confined to the right eye. The unaided visud acuity was $6 / 18$ in the right eye and $6 / 12+2$ in the left. The right anterior chamber was visibly shalie ower than the left. Right fundoscopy revealed a high retinal detachment inferiorly. The or serrata was raised and easily visible without scleral indentation around most of the peripheral fundus through a semi-dilated pupil. The paramacular area showed striate folds compatible with posterio choroidal detachment. No retinal breaks were seen. The left fundus was normal.

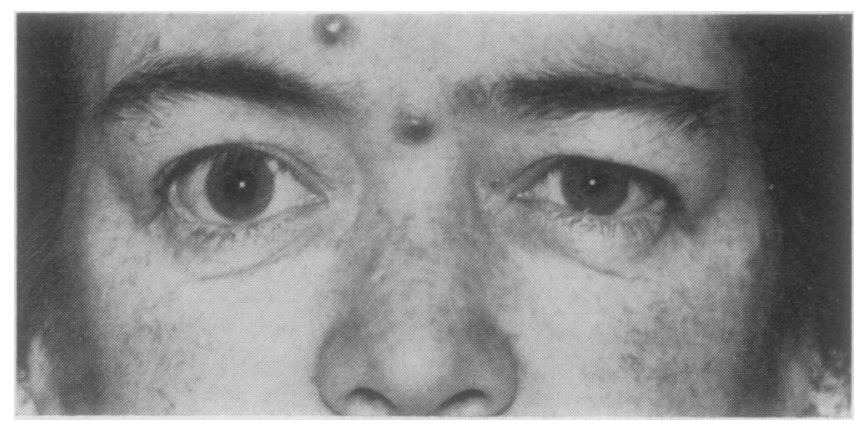

FIG. I Patient's appearance ato first examination showing bilateralo exophthalmos and retraction of right. upper lid.

Investigations

OCULAR

Anterior chamber depth (using Haag-Streit measuring device) $: 2 \mathrm{~mm}$. right; $2 \cdot 8 \mathrm{~mm}$. left.

Applanation tonometry: $15 \mathrm{~mm}$. $\mathrm{Hg}$ right; $20 \mathrm{~mm}$. $\mathrm{Hg}$ left.

Perimetry: Right showed minimal annular constriction of the visual field with accentuation of the fief loss above and two paracentral scotomata-all compatible with the fundus abnormalities.

Subretinal fluid: Shown to shift to the most dependent part of the globe.

Transillumination: normal.

$P_{32}$ uptake: probably normal. 
OTHER INVESTIGATIONS

Serum cholesterol: $375 \mathrm{mg}$. per cent.

Protein-bound iodine: $2 \cdot 0 \mu \mathrm{g}$. per cent.

Thyroid antibodies: absent from serum and cerebrospinal fluid.

I 131 uptake at 24 hours : 4 per cent. of tracer dose (a very low uptake confined to the lingual thyroid)

Electrocardiogram: flat $\mathrm{T}$ waves consistent with hypothyroidism.

Cerebrospinal fluid protein: raised at $73 \mathrm{mg}$. per cent., otherwise normal and under normal pressure.

Skull $x$-ray: markedly expanded sella turcica $(2 \cdot 2 \times 1 \cdot 8 \mathrm{~cm}$.) (Fig. 2).

Thyroid-stimulating hormone: more than 2,00o microunits/ml. (normal being less than 20 by the immunoassay method used in this hospital).

Total urinary gonadotrophins: normal at approximately $20 \mathrm{mg}$. International Reference Preparation - Human Menopausal Gonadotrophin/24 hrs.

In response to hypoglycaemia human growth hormone rose to $7.4 \mathrm{~m} \mu \mathrm{g} . / \mathrm{ml}$. and cortisol to 13.7 $\mu \mathrm{g}$./ $100 \mathrm{ml}$. The last two figures are slightly lower than expected in normal individuals, but are acceptable in a subject with primary myxoedema.

\section{Diagnosis}

Thus the patient was clearly shown to be hypothyroid with probable secondary pituitary hyperplasia. The ocular diagnosis was felt to be spontaneous annular choroido-retinal detachment with consequent shallowing of the anterior chamber and hypotension.

\section{Treatment}

This was begun with thyroxine $0 \cdot 05 \mathrm{mg}$. daily, increasing slowly; 2 or 3 weeks later the choroidoretinal detachment was virtually gone, visual acuity had returned to normal, and the paracentral scotomata had disappeared. The right anterior chamber deepened pari passu with the absorption of the uveal effusion; the measurements are shown in the Table.

It is also interesting that the right anterior chamber could be made to deepen whilst the choroidoretinal detachment was still present and before treatment with thyroxine was begun. With the right pupil in the mid-dilated position (as in Fig. I), the anterior chamber deepened to $2.60 \mathrm{~mm}$. Assuming fractional alteration only in the shape of the presbyopic lens, this means an antero-posterior lens

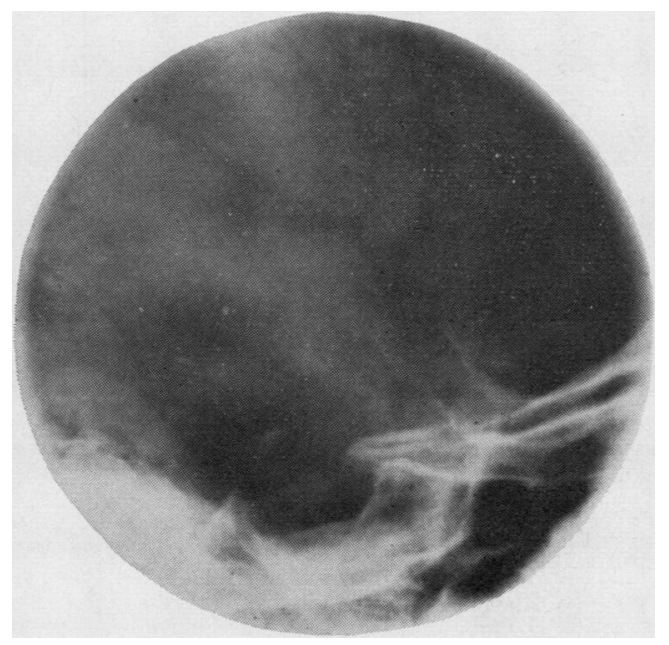

Table Anterior chamber depth (mm.)

FIG. 2 Skull $\times$ ray, showing markedly expanded sella turcica

\begin{tabular}{|c|c|c|c|}
\hline Eye & & Right & Left \\
\hline Before treatmen & & $2 \cdot 00$ & $2 \cdot 80$ \\
\hline After thyroxine & $\begin{array}{l}\text { I wk } \\
3 \text { wks } \\
5 \text { wks }\end{array}$ & $\begin{array}{l}2 \cdot 55 \\
2 \cdot 65 \\
2 \cdot 90\end{array}$ & $\begin{array}{l}2 \cdot 85 \\
2 \cdot 85 \\
2 \cdot 90\end{array}$ \\
\hline
\end{tabular}


shift of about $0.6 \mathrm{~mm}$. We have observed abnormal lens mobility in "inverse glaucoma" (unpu得 lished data) and the latter seems clearly akin to or the same as "malignant glaucoma". In te series reported by Schepens and Brockhurst (1963), it was noted that one patient did have "malignant glaucoma" and the basis for this may well have been an unduly mobile lens.

The level of thyroid-stimulating hormone in the serum after 2 to 3 weeks treatment with thyroxi was down to measurable levels at 150 microunits $/ \mathrm{ml}$.

\section{Discussion}

The ocular features of the case described clearly fit the description given by Schepens and Brockhurst (1963). They frequently noticed a shallow anterior chamber but did not include this sign amongst the prime signs of the syndrome. We feel this sign should prgs bably be included among the cardinal features of the syndrome, especially since it possiby. predisposes the eye to "inverse" or "malignant" glaucoma and may call for prolonge्ध mydriatic treatment. Our patient had clearly demonstrable shallowing of the anterigr chamber with abnormal lens mobility.

The patient also had raised cerebrospinal fluid protein, a sign frequently noticed by Schepens and Brockhurst among their patients. This figure is frequently raised $\underset{\rightarrow}{\longrightarrow}$ myxoedema so that its significance here links with the patient's medical status and raise query as to the thyroid function of Schepens and Brockhurst's patients.

Schepens and Brockhurst (1963), Graham (1958), and Davenport (1958) each referre⿻ to one female case, so that the condition has previously been seen in women although the number of male cases far exceeds that of female cases. Again, most cases reported afe either bilateral at first sight, or go on to show signs in the previously unaffected eye; it mof be that a second uveal effusion in the contralateral eye was forestalled by treatment wi thyroxine in our case.

This patient seems to us to be of unique importance. She appears to be the first clearl\% defined case of spontaneous choroido-retinal detachment (uveal effusion) due to my oedema. The syndrome may be analogous to the pleural, pericardial, and peritone? effusions which have all been described in myxoedema. It would seem that patients pre: senting with spontaneous choroido-retinal detachment clearly deserve investigation of the thyropituitary axis.

\section{Summary}

A case is reported of spontaneous annular choroido-retinal detachment caused by my oedema and cured by treatment with thyroxine.

Our thanks and gratitude are due to Dr. R. Hall for his generous help in the endocrinological investigation ard treatment of this patient, who was admitted under the care of Mr. N. Manson.

\section{References}

DUKE-ELDER, s. (1966) "System of Ophthalmology", vol. 9, p. 939. Kimpton, London

GRAham, P. A. (1958) Trans. ophthal. Soc. U.K., 78, 359

DAVENPORT, R. (1958) Discussion of Graham, p. 370

RIDLEY, H. (1958) Discussion of Graham, p. 37 I

Lewallen, w. m. (1957) Amer. F. Ophthal., 43, 679

ROSEN, E., and LYNE, A. (1968) Ibid., 65, 509

SCHEPENS, C. L., and BROCKHURST, R. J. (1963) Arch. Ophthal. (Chicago), 70, I89

StAllard, H. B. (1954) Brit. J. Ophthal., 38, I I 5 